\title{
To drain or not to drain after thyroid surgery: a randomized controlled trial at a tertiary Hospital in East Africa
}

\author{
Kalemera Ssenyondo E, Fualal J, Jombwe J, *Galukande M \\ Department of Surgery, College of Health Sciences, Makerere University, Kampala, Uganda
}

\begin{abstract}
Introduction: In many facilities, drains are routinely inserted after thyroidectomy with the aim of preventing hematoma formation and accumulation of seroma. The continued use of drains may be based more on tradition rather than proven scientific evidence.

Objective: To assess the benefit of drain use after thyroidectomy by determining; length of hospital stay, post operative pain and wound sepsis.

Methods: This was a randomized controlled trial, carried out at a tertiary national referral hospital (Mulago, Kampala). Over a 6 month period in 2011, we recruited 68 patients. Socio-demographic information and clinical parameters were recorded. Outcomes measures were evaluated. Data were double entered into epidata version 3.1.1 and analyzed using STATA version 10.0. Ethical approval was secured.

Results: Mean age of participants was 46 and 43.7 years in drain and no drain arm respectively. Most participants were female. Mean duration of hospital stay after thyroidectomy was significantly higher among the drain arm as compared with the no drain arm $[2.41( \pm 0.89)$ vs $1.71( \pm 0.76)$ days $(\mathrm{p}=0.0008)]$. One patient (drain arm) had wound infection. The pain score on the postoperative day was statistically higher among in the drain arm than the no drain arm $[5.71$ vs $2.53(\mathrm{p}=$ 0.001)].

Conclusion: Not inserting a drain post operatively after thyroid surgery was associated with short hospital stay and less operative pain. Results of this study do not support routine drainage after thyroid surgery.

Key words: thyroid surgery, drains, outcomes

ClinicalTrials.gov Identifier: NCT01729741

African Health Sciences 2013; 13(3): 748 - 755 http://dx.doi.org/10.4314/ahs.v13i3.33
\end{abstract}

\section{Introduction}

Thyroidectomy is one of the most commonly performed operations in general surgery ${ }^{1}$. Available data seem to suggest an association between nodrain usage and a shorter duration of hospital stay. Seung et $\mathrm{al}^{2}$ found that the time to discharge after thyroidectomy was significantly shorter in the no drain group compared to the drain group. Similar results were recorded in a study conducted by Davari et $\mathrm{al}^{3,4,5}$. Hyoung et $\mathrm{al}^{6}$ reported the incidence of hematoma formation post- thyroidectomy to be varying between $0.3-4.3 \%$. Tahsin et $\mathrm{al}^{1}$ reported that post-thyroidectomy bleeding is as rare as $0.3 \%-1.0 \%$. The fear of an hematoma enlarging and obstructing the airway and causing difficulty in breathing, prompts many surgeons to use drains routinely after any type of thyroid surgery. The main reason is to drain off a possible postoperative haematoma,

*Correspondence author:
Moses Galukande
Department of Surgery, College of Health Sciences
Makerere University
Kampala, Uganda
Email: mosesg@img.co.ug

which may compress the airway and produce respiratory failure ${ }^{1,4,7,8}$.

A prospective study conducted by Tahsin et $\mathrm{al}^{1}$ verified that routine use of drains after thyroidectomy is not effective in decreasing the rate of postoperative complications. On the other hand, the use of drains prolongs hospital stay; increases postoperative pain and may be associated with an increased risk of infection complications. However, studies which seem to suggest no benefit of drainage insertion after uncomplicated thyroidectomy were conducted in developed countries.

Whereas in developed countries people are likely to report to hospitals when their goiters are very small, people in resource limited settings do so much later when goiters are of much bigger sizes. This study therefore, aimed at comparing the patient outcomes with drain and no-drain insertion methods after thyroidectomy in a resource limited setting. 


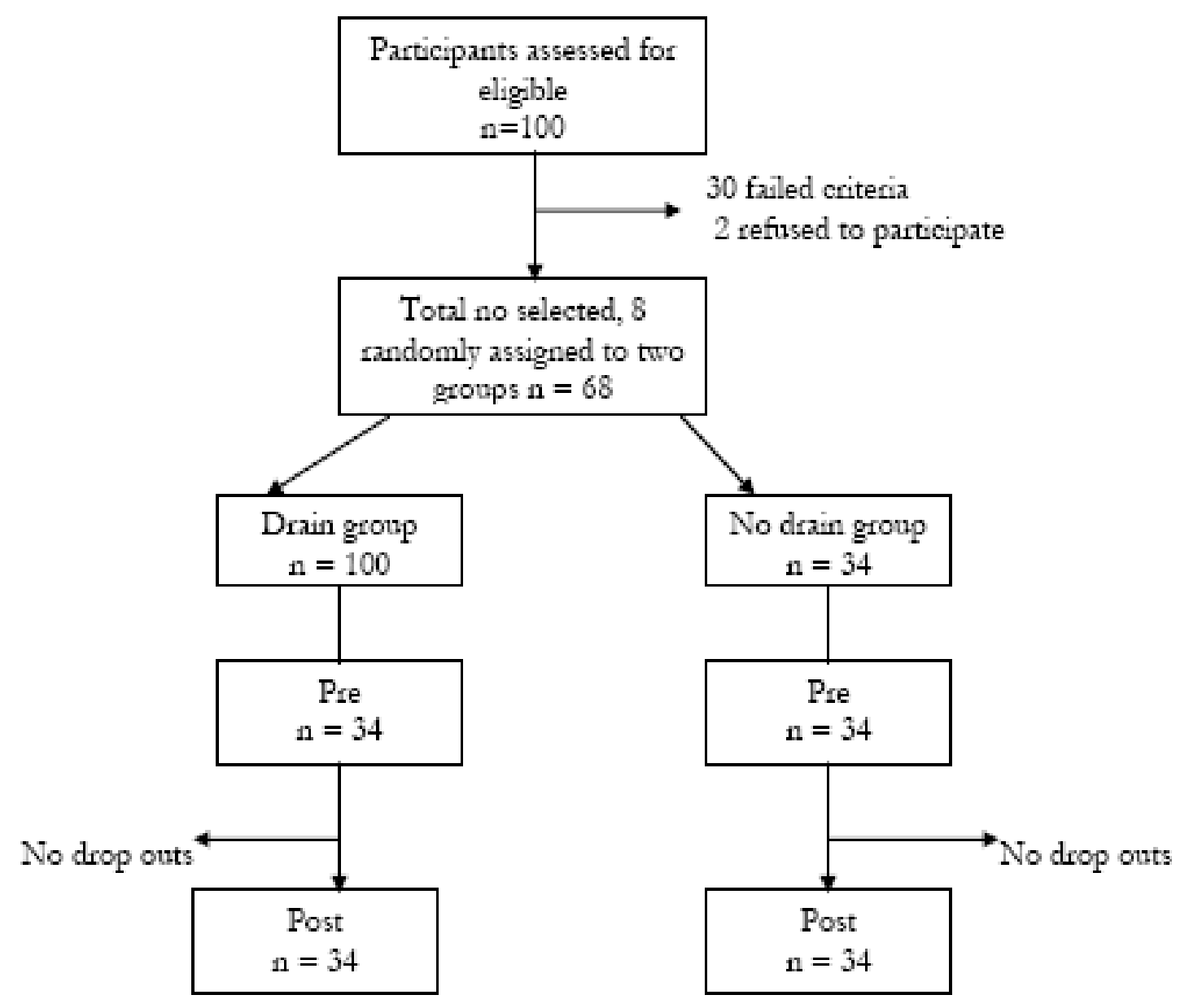

Figure 1: Study trial profile

\section{Methods}

\section{Study design}

The study was an open randomized controlled trial, with equal allocation of participants in each arm.

\section{Study setting}

This study was carried out at Mulago, Uganda's National Referral and Makerere University teaching Hospital located in the capital city, Kampala.

\section{Study participants}

All adult patients with goiters who were eligible for thyroidectomy

\section{Study population}

All adult patients aged between 18 to 79 years who attended the endocrinology outpatient clinic and had been diagnosed with goiter.

\section{Inclusion criteria}

All adult patients aged between 18 to 79 years with a diagnosis of goiter who consented to participate in the study.

\section{Exclusion criteria}

We excluded patients with goiter who had a history suggestive of bleeding tendencies, recurrent goiter, and thyroid cancer with fixation of the thyroid gland to surrounding structures and had uncontrolled comorbidities such as diabetes mellitus (DM) and hypertension (HT).

\section{Sampling procedure}

Patients with goiters seen in the surgical outpatient departmentwere interviewed and assessment made. Screening of potential study patients for suitability for surgery included history taking, physical examination, and investigations. 


\section{Sample size estimation}

A sample size of 68 was calculated using a web based statistical package (OpenEpi), Version 2, open source calculator SSCohort (http://www.openepi.com/ OE2.3/SampleSize/SSCohort.htm).

In the calculation we assumed $95 \%$ confidence intervals, $80 \%$ power.

We also assumed that the mean duration of hospital stay in those having the drain inserted would be 9.3 days (SD 4.6 according to study by Seung et al ${ }^{2}$.

Assuming an effect size of $25 \%$ the difference in mean duration between the two groups was 2.33 .

The minimum sample size required for this study was 62 participants. Considering 10\% loss to follow up, the sample size became 68 participants (34 in each arm).

\section{Generation of randomization sequence, allocation and randomization}

Eligible subjects were randomly assigned to either the drain or no drain arm of the trial after thyroidectomy. The allocation sequence was computer generated; blocks of variable sizes were used ranging from 4-10 participants. The computer generalized randomization identification numbers were placed in small opaque envelopes. Big opaque envelopes were used to form blocks where the small opaque envelopes were put. The envelopes were kept by the operating room in-charge nurse (independent of the study). At the end of each thyroidectomy, an envelope from the block was opened and the participants assigned to the drain or no drain group according to what the envelope finings dictated.

The study variables were; drain insertion, length of hospital stay pain, and wound sepsis.

\section{Data collection}

Patients who attended the thyroid clinic during the study period were screened; those with thyroid disease which required surgical intervention were briefed about the study. Patients that expressed interest in participating in the study were given more details about the study and surgery and asked to provide informed consent. The patients were operated on by three experienced specialist surgeons with special interest in thyroid/endocrine surgery. All relevant information obtained from the patient from the time of recruitment to discharge was recorded on data collection tools. Filled data collection tools were kept under lock and key by the principal investigator. A visual scale analogue was used for pain. A standard patient care including discharge protocol was followed. It was technically not possible to blind the doctor discharging the patient to what group the study participant fell.

\section{Data Management}

The data were cleaned, coded, and double-entered in Epidata version 3.1 and exported to STATA version10.0 for data analysis.

\section{Data analysis}

Assessment of accuracy of randomisation

The closed sequence method of random number generation was used. The output from the random number generation was checked to ensure that the sequence showed no evidence of non-randomicity. This was done by checking the numbers for independence to ensure that there were no particular sequential patterns.

\section{Univariate analysis}

Continuous data such as age, and duration of hospital stay was summarized as means ( \pm standard deviation), medians (inter-quantile range). All data for continuous variables which was normally distributed, we used student $\mathrm{t}$ - test to assess significant difference. Chi square and Fisher's exact test was used for all categorical variables where appropriate.

\section{Bivariate analysis}

Bivariate analysis was done and results were reported as risk ratios. We further assessed the effect of drain on duration of hospital stay using Cox hazard regression model.

\section{Ethical consideration}

Institutional ethical approval was obtained from Ethics and Research Committees of Makerere University College of Health Sciences and Mulago hospital.

\section{Results}

Up to one hundred participants were assessed for eligibility; of which 30 did not meet inclusion criteria and two refused to participate. Sixty eight participants were recruited, equally randomized to two arms, followed up and analyzed as shown in figure 1. 
Table 1: Socio demographic characteristics of the participants

\begin{tabular}{|c|c|c|c|c|}
\hline Variable & Category & Drain N (\%) & No-drain N (\%) & P value \\
\hline \multirow[t]{2}{*}{ Age (years) } & $($ Mean \pm SD) & $46(8.8)$ & $43.5(12.6)$ & $0.34 \dagger$ \\
\hline & Range & 31 - 65years & 21 to 65 years & \\
\hline \multicolumn{5}{|l|}{ Sex } \\
\hline & Male & $3(50)$ & $3(50)$ & $1.00^{\mathrm{X}}$ \\
\hline & Female & $31(50)$ & $31(50)$ & \\
\hline \multicolumn{5}{|l|}{ Occupation } \\
\hline & Salary/wage & 5 & 4 & 0.18 \\
\hline & Peasant & 22 & 21 & \\
\hline & Business & 6 & 4 & \\
\hline & Others * & 1 & 5 & \\
\hline \multicolumn{5}{|c|}{ Ethnic group } \\
\hline & Bantu & 22 & 21 & 0.59 \\
\hline & Luo & 6 & 7 & \\
\hline & Nilo hamates & 4 & 4 & \\
\hline & Others** & 2 & 2 & \\
\hline
\end{tabular}

t t-test ${ }^{\mathrm{x}}$ Chi-square test

Others* House wife 5 \& student 1; [Bantu ethnicity: Baganda (19), Banyankole (7), Bakiga (7), Bagisu (4), Basoga (2), Batooro (2), \& Munyoli (1); Luo ethnicity: Acholi (3), Aruru (7); Nilohamites ethnicity: Ateso (1) \& Sabinyi (7); and Others** includes Congolese (1); Rwandese (1), Madi (1) \& Kakwa (1)].

The majority of the patients that were recruited in this study were young. The mean age (standard deviation) of participants was 45.3(8.8) and 43.7(12.6) years in the drain and no drain arm. More females than males were recruited (female: male 9:1). Over $60 \%$ of the patients were peasants and of the Bantu group. There was no statistically significant difference in all the socio demographic characteristics in the two arms of this study.

As illustrated, thyroidectomies that were accompanied by drain insertion took a statistically longer duration than those that involved no drain insertion $(\mathrm{p}=0.02)$. Likewise, total and partial lobectomies (both partial thyroidectomies) were performed more frequently in the drain-use arm while lobectomies were more frequently done in the no-drain arm. This difference was statistically significant $(\mathrm{p}=0.011)$.

Tables 1 and 2 show that randomization was a success with the exception of type of surgery that showed a statistically significant relationship with drain insertion.
As shown in table 2, the duration of hospital stay was significantly higher among the patients who received a drain as compared with those who didn't $(p=0.0008)$. There was no statistically significant difference between the frequencies of wound sepsis after 24 hours postoperatively in the two groups.

Table 4 examines the impact of drain insertion on the occurrence of various post operative (thyroidectomy) complications. On the first postoperative day, pain was significantly more severe in the drain as compared with the no drain arm $(<0.001)$. There was no statistically significant difference in the occurrence of all other post operative complications in the two study groups. 
Table 2: Assessing the success of randomization

\begin{tabular}{|c|c|c|c|c|}
\hline Variables & Drain & No Drain & $95 \%(C I)$ & P-value \\
\hline \multicolumn{5}{|l|}{ Continuous } \\
\hline $\begin{array}{l}\text { Duration of goitre (years) before } \\
\text { presenting for care mean }( \pm S D)\end{array}$ & $9.8(6.4)$ & $9.9(8.2)$ & $0.03(-3.5-3.6)$ & $0.99 \dagger$ \\
\hline Goitre volume mean $( \pm \mathrm{SD})$ & $499(768)$ & $424(754)$ & $-74(-443-294)$ & $0.34 \dagger$ \\
\hline Temperature mean $( \pm \mathrm{SD})$ & $36.1(0.27)$ & $36.1(0.19)$ & $-0.04(-0.16-0.71)$ & $0.45 \dagger$ \\
\hline Categorical & $\mathrm{N}(\%)$ & $\mathrm{N}(\%)$ & $\mathrm{X}^{2}(\mathrm{df})$ & \\
\hline \multicolumn{5}{|l|}{ Pressure symptoms } \\
\hline Yes & $24(59)$ & $17(41)$ & $3.01(1)$ & $0.08^{\mathrm{X}}$ \\
\hline No & $10(37)$ & $17(63)$ & & \\
\hline \multicolumn{5}{|l|}{ Texture } \\
\hline Nodular & $6(50)$ & $6(50)$ & $0.00(1)$ & $1.00^{\mathrm{X}}$ \\
\hline Multinodular & $28(50)$ & $28(50)$ & & \\
\hline \multicolumn{5}{|l|}{ Cytology } \\
\hline Benign & $29(47)$ & $32(53)$ & $1.43(1)$ & $0.23^{\mathrm{X}}$ \\
\hline Malignant & $5(71.4)$ & $2(28.6)$ & & \\
\hline \multicolumn{5}{|l|}{ Tracheal deviation } \\
\hline Yes & $22(50)$ & $22(50)$ & $0.00(1)$ & $1.00^{\mathrm{X}}$ \\
\hline No & $12(50)$ & $12(50)$ & & \\
\hline \multicolumn{5}{|l|}{ Surgery type (Thyroidectomy) } \\
\hline Total & $3(100)$ & $0(0.00)$ & $8.69(2)$ & $0.011 !$ \\
\hline Partial & $25(58)$ & $18(42)$ & & \\
\hline Lobectomy & $6(27.3)$ & $16(73)$ & & \\
\hline \multicolumn{5}{|l|}{ Perioperative complications } \\
\hline \multicolumn{5}{|l|}{ RL nerve injury } \\
\hline Yes & $0(0.0)$ & $0(0.0)$ & $0.00(1)$ & $1.00^{\mathrm{X}}$ \\
\hline No & $34(50)$ & $34(50)$ & & \\
\hline \multicolumn{5}{|l|}{ Parathyroid } \\
\hline Yes & $1(100.0)$ & $0(0.00)$ & $1.00(1)$ & $0.31^{\mathrm{x}}$ \\
\hline No & $33(49)$ & $34(51)$ & & \\
\hline \multicolumn{5}{|l|}{ Tracheal Injury } \\
\hline Yes & $0(0.0)$ & $0(0.0)$ & $0.0(1)$ & $1.00^{\mathrm{X}}$ \\
\hline No & $34(50)$ & $34(50)$ & $34(50.00)$ & \\
\hline
\end{tabular}

Table 3: Assessment for objectives (effect of drain on duration of hospital stay; and infection after $24 \mathrm{hrs}$ to discharge and at $7^{\text {th }}$ day postoperative)

\begin{tabular}{lllll}
\hline Variables & Drain & No Drain & $\mathbf{9 5 \%}(\mathbf{C I})$ & P- value \\
\hline Ward duration mean $(\mathrm{SD})$ & $2.41(0.89)$ & $1.71(0.76)$ & $-0.71(-1.10--0.30)$ & $0.0008 \dagger$ \\
Wound sepsis $>$ 24hrs to discharge & $\mathbf{N}(\mathbf{\%})$ & $\mathbf{N}(\mathbf{\%})$ & $\times^{\mathbf{2}}(\mathbf{d f})$ & $1.0^{\mathrm{x}}$ \\
Yes & $0(50)$ & $0(50)$ & $0(1)$ & \\
No & $34(50)$ & $34(50)$ & & \\
$7^{\text {th }}$ day postoperative & & & & \\
Yes & $1(100)$ & $0(0)$ & Infinity & \\
No & $30(49)$ & $34(51)$ & & \\
\hline
\end{tabular}

†t-test, ${ }^{\mathrm{x}}$ Chi-square test 
Table 4: Assessment of the effect of drain insertion on complications

\begin{tabular}{|c|c|c|c|c|}
\hline Variables & Drain & No Drain & $95 \%($ CI ) & P-value \\
\hline \multicolumn{5}{|l|}{ Pain scores } \\
\hline $\begin{array}{l}1^{\text {st }} \text { postoperative day } \\
\text { (mean } \mathrm{SD} \text { ) }\end{array}$ & $5.71(2.37)$ & $2.53(2.23)$ & $-3.18(-4.30--2.05)$ & $<0.001 \dagger$ \\
\hline $7^{\text {th }}$ postoperative day & $0.29(1.03)$ & $0.09(0.51)$ & $\begin{array}{l}-0.21(-0.60) \\
\mathbf{x}^{2}(\mathbf{d f})\end{array}$ & $0.30 \dagger$ \\
\hline \multicolumn{5}{|l|}{$<24$ hours } \\
\hline \multicolumn{5}{|l|}{ Change voice } \\
\hline Yes & $4(67)$ & $2(33)$ & $0.73(1)$ & $0.39^{\mathrm{x}}$ \\
\hline No & $30(48.39)$ & $32(52)$ & & \\
\hline \multicolumn{5}{|l|}{ Hematoma } \\
\hline Yes & $0(50)$ & $0(50)$ & $1.00(1)$ & $1.00^{\mathrm{x}}$ \\
\hline No & $34(50)$ & $34(50)$ & & \\
\hline \multicolumn{5}{|l|}{ Laryngeal edema } \\
\hline Yes & $2(50)$ & $2(50)$ & $0.00(1)$ & $1.00^{\mathrm{x}}$ \\
\hline No & $32(50)$ & $32(50)$ & & \\
\hline \multicolumn{5}{|l|}{$>24$ hours to discharge } \\
\hline \multicolumn{5}{|l|}{ Hematoma } \\
\hline Yes & $1(100)$ & $0(0)$ & $1.05(1)$ & $0.31^{x}$ \\
\hline No & $33(48)$ & $34(52)$ & & \\
\hline \multicolumn{5}{|l|}{ Seroma } \\
\hline Yes & $3(60.0)$ & $2(40)$ & $0.22(1)$ & $0.64^{\mathrm{x}}$ \\
\hline No & $31(49)$ & $32(51)$ & & \\
\hline
\end{tabular}

\section{Discussion}

The socio demographic characteristics, clinical features and perioperative complications show that the randomization was successful see table 1 and 2 . Although the type of surgery had shown to be significantly associated with the drain insertion, and therefore could have been a possible confounder that could influence the outcome of duration of hospital stay. Further assessment found that the type of surgery was not significantly associated with the duration of hospital stay.

The majority of the participants were young with a mean age $( \pm S D)$ of $46(8.8)$ years in the drain arm and 43.5(12.6) years in the no-drain arm.

The higher percentage of females (90\%) recruited in this study is in agreement with previous studies including the work of Tahsin et $\mathrm{al}^{1}$ and Davari et $\mathrm{al}^{3}$ in which the majority of participants were females, $79.3 \%$ and $78.8 \%$ respectively.

The finding that the Baganda were the majority followed by Banyankole in this study, contradicts earlier findings by Gabriel S.B et $\mathrm{al}^{9}$ in which goiters were reported to be commoner among the people who reside in highland areas such as Kabaale, Kapchorwa and Kasese which are said to African Health Sciences Vol 13 Issue 3 September 2013 be deficient of iodine. This difference in the findings could be explained by the fact that this study was conducted in Mulago hospital which is in Buganda region and therefore could have created a selection bias. The effect of the drain insertion on the duration of hospital stay or any of the other outcomes is unlikely to be affected by the tribe represented here. As regards the symptoms and signs at presentation, most of the participants had tracheal deviation and mean volume (standard deviation) of the thyroid mass was 498.5 ( \pm 768.4$)$ in the drain group and 424.1 $( \pm 754.1 .4)$ in the no drain group. This implies that the majority of the participants presented late with high grade goiter having developed pressure symptoms; notably dysphasia and tracheal deviation.

\section{Relationship between type of intervention and duration of hospital stay}

In our study, the mean duration $( \pm S D)$ of hospital stay after thyroidectomy among participants who did not receive a drain was shorter as compared with those who received a drain $[1.71( \pm 0.76)$ compared to $2.41( \pm 0.89)$ days respectively]. This 
difference was significant $(p=0.0008)$ implying that inserting a drain in the thyroid bed significantly increased the length of hospital stay as compared to not inserting a drain. The longer duration of hospital stay leads to high bed occupancy with its attendant and health facility costs, thus straining further the meager health resources of our country. These findings are in agreement with previous studies ${ }^{1-5,11}$ which revealed that inserting a drain in thyroid bed after thyroid surgery increases duration of hospital stay. These findings are however contrary to the traditional thinking that drain insertion post thyroidectomy frequently prevents haematoma which would complicate surgery through predisposition to air way obstruction ${ }^{6}$. Drains may however still be useful for patients with known history of bleeding disorders who were not included in our study and where substantial dead space is left after radical neck dissection.

\section{Relationship between type of intervention and wound sepsis}

In this study, postoperative wound sepsis was uncommon in both the drain and no-drain use arms. Only one patient in the drain group had wound infection postoperatively and none in the no-drain group had evidence of infection. These results were however not statistically significant from the first postoperative day to discharge. Earlier studies ${ }^{3,5}$ documented an increased prevalence of post operative wound sepsis following drain insertion.

\section{Other post operative complications of thyroidectomy}

With the exception of pain during the first 24 hours of surgery, there was no statistically significant difference in the complications reported between the two groups. The mean $( \pm S D)$ of the pain as measured by visual analog scale on the first postoperative day was 5.71(2.37) in the drain group and 2.53(2.23) in the non drain group $(\mathrm{p}=<0.001)$ which was statistically significant. These complications however reduced in subsequent days in both arms. Although other ${ }^{2,4}$ who found out that drain insertion after thyroid surgery is associated with more complications our study was only able to demonstrate a higher pain score in the drain insertion group within the first post operative 24hours compared to the no drain insertion group.

\section{Limitation of the study}

The failure to demonstrate a significant relationship between the drain insertion and the wound infection may have been due to among other factors the sample size used in this study. Larger sample sizes using multicentre recruitment sites (which are beyond the scope of this study due to logistical limitations) could be explored.

There was a small risk of patients being predisposed to acquiring infection after surgery as a result of over staying on the ward prior to surgery. This was however avoided by admitting fully investigated participants at most two days prior to the surgery.

\section{Conclusions}

Insertion of drains after thyroid surgery increased the length of hospital stay and pain. Routine insertion of drains after thyroidectomy does not seem to be supported by findings of this study. An urgent review of the practice of routine insertion of drains after thyroidectomy is warranted.

\section{References}

1. Tahsin C, Tamer A, Ozgur T, Hakan C, Bora U, Arzu K, Suha A. Drainage after total thyroidectomy or lobectomy for benign thyroidal disorders. Journal of Zhejiang University Science. 2008; 9(4):139-323.

2. Seung WL, Eun CC, Yong ML, Jae Y L, Shi CK, Yoon Woo Koh. Is Lack of Placement of Drains After Thyroidectomy Safe? 2006. The American Laryngological, Rhinological and Otological society, Inc.

3. Davari HR, Malek Hossin SA. Thyroidectomy with and without Drainage. MJIRC Vol.7. No.1.

4. Khanna J, Mohil RS, Mittal MK, Sahoo M, Magan M. Saturday, May 2006. Is the routine drainage after surgery for thyroid necessary? A prospective randomized clinical study. [ISRCTN63623153]. BMC Surg. 2005; 5:11. Doi: 10.1186/1471-2482-5-11. [PubMed]

5. Nuraydin O, Mehmet O, Ahmet G, Gomceli I and Raci A. Should the thyroid bed be drained after thyroidectomy? Langenbeck's Archives of Surgery. 2006; 391: 1435-2457 Number ISSN: 1435-2443 (Print). DOI: 10.1007/s00423-0060048-2.

6. Hyoung SL, Sung WK, Young WC, Yo Han P, Kang DL. Patterns of Post-thyroidectomy Hemorrhage. Clinical and Experimental Otorbinolaryngology 2009; 2(2): 72-77 
7. Matory YL, Spiro RH. Wound bleeding after head and neck surgery. J Surg Oncol. 1993; 53(1):17-19. doi: 10.1002/jso.2930530107.

8. Shaha AR, Jaffe BM. Selective use of drains in thyroid surgery. J Surg Oncol. 1993; 52(4):241243. doi: $10.1002 /$ jso.2930520409

9. Bimenya GS, Olico-Okui, Kaviri D, Mbona N, Byarugaba W. Monitoring the severity of iodine deficiency disorders in Uganda. Afri Health sci. 2002 August; 2(2): 63-68.

10. Adam MB, Terris DJ. The changing Face of Thyroid surgery. Review of Endocrinology. 2008

11. Wihlborg $\mathrm{O}$, Bergljung L, Mårtensoon $\mathrm{H}$. To drain or not to drain in thyroid surgery. A controlled clinical study. Arch Surg 1988 Jan; 123(1): 40-1 